\title{
LA EVOLUCIÓN DEL CASTELLANO EN LOS ESTADOS UNIDOS
}

\author{
Alfredo González \\ Buró de Educación de Chicago. Illinois. Estados Unidos.
}

"Hay montañas en estas tierras de la nueva España que tienen mucho heno muy verde, son airosas y ventosos, húmedas y hiela; son lugares tristes y solitarios y llorosos...cavernosos y riscosos y pedregosos y lodosos... Hay lugar de tierra dulce y tierra amarilla, y lugares de grandes cuestas y de grandes lomas rincosas llenas de heno y de árboles muy espesos y también ralos. Y hay también llanuras y muchos maderos, y lugares espantosos y temerosos donde moran toda suerte de bestias..., lugares de grandes fríos y heladas donde se para yerto el cuerpo, lugar donde las bestias comen a los hombres, y hay grandes selvas tupidas y enmarañadas donde hace calor de infierno $y$ que no dan paso a tránsito... y lugares hermosos y vistosos, nunca vistos ni visitados, y hay muchas maneras de bestias, animales, árboles, frutas y yerbas..."

"Hay en esta tierra un animal que se dice cóyoth al cual algunos españoles le llaman zorro, y otros le llaman lobo, y según sus propiedades a mi ver ni es lobo ni zorro, sino animal propio de esta tierra... Hay otro animalejo que llaman mapachtli..., que quiere decir viejilla en la lengua de esta tierra indiana, y que tiene las manos y la pies como persona y destruye los maizales y cómese lo verde de adentro...

"Y hay también todas maneras de raíces y frutas buenas para comer y sabrosas, y plácidas por su belleza... hay raíces buenas de comer como está dicho que se hacen como nabos debajo de la tierra, la cuales llaman camotli, éstas son las batatas de esta tierra y cómense cocidas, crudas y asadas ... y hay otra raíz que se come cruda que se llama jicama, que son blancas y dulces y 
matan mucho la sed... y hay un árbol que se llama auácatl, y llámase así su fruta que es negra por de fuera y verde y blanco de por dentro; de hechura de corazón y tiene un cuesco dentro también con hechura de corazón,... y toda sarta de otras frutas y cosas maravillosas hay en estas tierras ... Y los pobladores son de nombre mexicatl... Y la causa del nombre según lo cuentan los viejos es que cuando vinieron a estas partes traían a un caudillo que se llamaba Mécith que es melt por el maguey, y citli por liebre, al que luego después que nació le llamaron Mécitli, porque múdose la c por $x$; y lo criaron en una penca de maguey; de allí en adelante llámose Mexicatl..."

Estos son fragmentos de la Historia General de las Cosas de Nueva España del fraile franciscano Bernardino de Sahagún durante la conquista y colonización de México.

Fue una dura empresa para los cronistas describir la exuberancia americana con la limitación de un castellano que no había salido del Viejo Mundo. Requeríase pues suma abundancia y riqueza de vocabulario para describir toda aquella grandeza que era América. Véase aquí como se usa un gran número de palabras para describir lo que era visto por primera vez por el español. Sahagún hace gran rodeo para describir lo que ve a su alrededor y logra trasmitirnos su total sorpresa antes estas cosas extrañas y maravillosas. Usa las palabras ya conocidas y compáralas con las cosas que ya se conocían en el viejo mundo, tratando a duras penas de dar una imagen cercana a la realidad.

Es claro entender ahora todos estos nombres porque ya se sabe de lo que se está hablando, pero pensemos por un momento; ¿cómo se imaginaría un europeo todo este mundo desconocido, sin tener ninguna referencia?

A principio estas descripciones de los cronistas fueron suficientes para dar la introducción de América al Viejo Mundo, pero al pasar el tiempo, e ir conociéndose más a fondo el Nuevo Mundo, la lengua española se vio obligada a admitir muchas de estos nuevos vocablos simplemente por falta de propios que describieran con exactitud de lo que se trataba. Muchos vocablos fueron a parar al castellano después de una adecuada "españolización", como era menester en los turbulentos tiempos de la colonización y la conquista, y para observar la armonía sonora. Así vemos que muchas voces modificaron su pronunciación para hacerlas más "propicias al castellano." Un buen ejemplo de ésto son las palabras indígenas terminadas en $t$. Podríamos citar algunas como camotli que pasó a ser camote; auácath aguacate; coyoctl, coyote; mexicth, mexicano, etc...

Algunos vocablos mantuvieron su nombre original debido a que su sonido "aparejaba al castellano" como es el caso de jicama. 
De muchas, sino de todas la lenguas aborígenes, expropió el castellano toda clase de nombres y expresiones para poder describir al europeo la grandeza americana. Nos quedan hoy del arahuaco, hablado en las Antillas, canoa, cacique, carey, caníbal, tabaco y yuca, entre otras. Del nahualt que predominaba en todo México, asumimos cacao, chocolate, hule, petate, jícara, tiza, etc. Del quechua hablado por las Incas heredamos alpaca, guano, cóndor, llama, macana, y muchas otras. Del araucano c mapuche al sur de Chile, gaucho, poncho, laucha, etc.

Sin duda que el castellano nunca fue el mismo después de la experiencia americana. Esta hibridación de la lengua, como podríamos llamarla, fue más bien el producto de la necesidad que tenían los españoles de entenderse con los aborigenes, que de la intensión deliberada de los conquistadores de borrar la cultura "bárbara" de los pueblos indígenas. No debemos olvidar que las culturas precolombinas estaban bien desarrolladas. Las lenguas nativas eran extensas y bien articuladas. Mucho más quizás que las lenguas modernas porque al nombrar algo el indio no solamente sabía de lo que estaba hablando sino que le daba al interlocutor una descripción, más o menos detallada del objeto o cosa en cuestión.

Considérese por ejemplo los nombres cocuyo, yagruma y yagua del arahuaco, lengua de los indios de Cuba. Estas palabras describían a plenitud de lo que se estaba hablando. El primero se refería "al que se alumbra a si mismo" para describir a estas luciérnagas tropicales que invadían las palmares en flor de las llanuras cubanas. Yaguma, por su parte, quería decir "gran gigante luminoso" y describía a la perfección a este árbol de gran tamaño que tiene plateado el envés de sus hojas y que resplandece bajo las luz de la luna. Yagua, se refería a "lo que sirve para muchas cosas" o "de lo que tiene muchos usos".

Desafortunadamente, existe muy poco escrito acerca de la lengua de los indios del Caribe, "por ser estos muy atrasados y simples, dados a la diversión y al ocio" como los describió el Gran Almirante. Otras culturas precolombinas pasaron a ser, con el paso del tiempo, más importantes a los ojos de los conquistadores por ser más desarrolladas y ricas. Afortunadamente, en el campo de Cuba se mantuvieron muchas leyendas recogidas por la tradición oral, y en la práctica religiosa. El uso de yerbas y ritos para hacer curaciones y conjuras expresan la relación del indio con el mundo circundante. $\mathrm{El}$ indio se cría parte de este mundo. En general, las culturas amerindias tenían una relación estrecha con la naturaleza que estaba muy bien expresada en su lengua. Sólo debemos fijarnos en cómo se hacían llamar los indios de Norteamérica, por ejemplo, para darnos cuenta de cuanto amaba el indio a la naturaleza. Red Cloud (nube roja) y Crazy Horse (caballo Loco) son qui- 
zás los más conocidos porque les hicieron la guerra al hombre blanco, pero también sabemos de otros como Pájaro Ligero y Loba Mansa, de la tribu de los Chicahominy. Estos indios pedían permiso antes de matar un búfalo, por ejemplo. Este respecto estaba implícito en la forma en que hablaba el indio, que expresaba una gran reverencia por el mundo circundante. Tono que no tenía el castellano del conquistador, que expresaba más bien la arrogancia del hombre blanco.

Desgraciadamente, los nombres españolizados derivados de estas palabras perdieron su carácter descriptivo con la asimilación castellana, y se perdió la reverencia al mundo circundante que venía de las lenguas originales. Ahora sólo sabemos, por ejemplo, cómo es el chocolate porque lo conocemos y lo hemos probado, pero el nombre en sí no nos dice nada de sus propiedades. Chocolatl quería decir "lo más valioso" o "precioso comestible," debido al valor del cacao que servía como dinero en el mercadeo en le mercado azteca.

No sé sabe por qué los indígenas nombraban las cosas dando un descripción de las mismas. ¿Habrían quizás algunos que podrían entender los nombres pero que no conocían el objeto o cosa descrita, y dependían de estas descripciones para saber de qué se estaba hablando?

Como he encontrado muy poco al respecto en toda mi investigación, he usado lo que he podido encontrar en la tradición oral en Cuba, ya casi extinta. Recuerdo que de niño mi abuela me contaba leyendas que provenfan de su bisabuelo que era mambí. Esta fuente, aunque parece ser auténtica por su diversidad y abundancia, no es científica. De todas maneras nos da una noción de la riqueza lingǘstica de las lenguas precolombinas y su influencia en el castellano moderno, que es lo que nos ocupa.

Lo que si es cierto era la riqueza cultural que existía en las culturas precolombinas. El emperador Moctezuma, por ejemplo, tenía a su disposición un gran zoológico con toda clase de animales procedentes de todo el imperio. Había también jardines botánicos con un sinnúmero de plantas y flores. Algo poco común en la España de ese tiempo.

Aunque la colonización fue sinónimo de la destrucción del patrimonio cultural precolombino, a mi modo de ver, la mezcla del lenguaje respondió más bien a necesidades prácticas y no a ninguna colonización lingüística deliberada sobre el indígena. Lo que sucedió con la religión sucedió también con el lenguaje. Con la diferencia de que los españoles, deliberadamente, trataron de reemplazar las creencias indígenas por el cristianismo, y aunque esta gestión fue en su mayor parte exitosa, no pudo eliminar completamente las creencias de los indios. Hasta hoy nos han llegado rituales y ceremonias que 
a pesar de que se han mezclado con el catolicismo, siguen vivas en muchas partes de América.

Aún más tuvo lugar con el lenguaje. $Y$ aunque a principio la comunicación entre españoles e indios era más bien a base de gestos y el uso del lenguaje corporal debido a la multitud de idiomas que existían, eventualmente las lenguas amerindias se adentraron en el castellano de forma definitiva.

Esta mezcla debe verse entonces como una necesidad de la gente común de resolver su propios problemas diarios. Podríamos decir sin temor a equivocarnos, que lo práctico es lo que le ha dado a la lengua su capacidad de crecimiento y diversidad, y no de modo alguno, la intensión del estudioso, que deben ir detrás de las generaciones recogiendo los vocablos nuevos, inventados por la gente en el quehacer diario de sus vidas, sin ningún ánimo de sabiduría. No olvidemos que la misma lengua escrita nació de la necesidad imperiosa de los sumarios de llevar control "por escrito" de lo que compraban y vendían. " $Q$ Que principio tan vulgar de tan grande invención humana!"; podría lamentarse el erudito melancólico.

El castellano, como el hombre español mismo, se prestó para la mezcla tanto lingüística como racial sin ningún reparo. Esta costumbre de mezclarse estaba muy arraigada en España y siguió sucediéndose después de la conquista. La lengua, en su afán de recogerlo todo es sus anales, nos dejó ésta expresión del coloquio popular cubano, por ejemplo, que denota muy bien el mestizaje de razas y eventualmente de lenguas: "La necesidad hace parir mulato," refiriéndose a lo que decían las negras libertas cubanas cuando se veían obligadas a tener un amante español para poder resolver su problema económico.

El español no puso reparo para mezclarse con los indios y después con los negros africanos. Como fue con la raza, fue también con el idioma.

Ya el castellano había admitido muchos vocablos antes de llegar a América. Un sinnúmero de adiciones estaban bien establecidas en el idioma. Estos habían llegado de las lenguas de las gentes que pasaron por este territorio, o de otros idiomas europeos. Del árabe había recogido el castellano muchas vocablos, dejando en sus anales la huella ineludible de la dominación mora sobre España. Y cuando ya los españoles se deshicieron de los moros, una nueva y poderosa influencia se abalanzó como un cañonazo sobre ellos. Empezó la conquista y colonización de América.

Pero la experiencia americana dio al traste con todo lo anterior. No ha habido nada en el mundo con tanta importancia para el desarrollo del lenguaje castellano como el descubrimiento.

Debido a la extensión del dominio español en América, la asimilación lingüística no podo ser uniforme. Existía tanta diversidad en el Nuevo 
Mundo que no era imposible llamar a una determinada cosa con el mismo nombre, aunque éste ya estuviera españolizado. Así fueron desarrollándose peculiaridades inherentes a cada zona o región lingüística. El castellano está saturado de este asombrosa diversidad. Hasta hoy nos llegan el uso de distintos vocablos para describir la misma cosa; Por ejemplo, llámase al camote en Cuba, boniato (voz que proviene de la lengua de los taínos). Llámesele cacahuate (cacauatl) en México a lo que los cubanos llamamos maní, y yautía a lo que nosotros conocemos como malanga o guaguí, dependiendo de la parte del país de que se trate. Los puertorriqueños dicen avanza, cuando los cubanos decimos apúrate, y los mexicanos dicen ándele, cuando queremos que la gente valla de prisa. Nosotros decimos "Hay Dios Mío", cuando queremos invocar al Altísimo, mientras que los boricuas dicen "Ay Bendito".

A pesar de todo ésto, el castellano americano moderno no es tan intrincado como lo fue en los tiempos de Bernal Díaz del Castillo y el Padre de las Casas, aunque sigue siendo un reto para los lingüistas de hoy.

Durante la segunda conquista que estamos llevando a cabo los hispanos en Norteamérica con la poderosa arma de la inmigración, las características del castellano hablado hoy en ese país son única en su naturaleza, y los que estamos expuestos a esta poderosa influencia no podemos hacer nada más que dejarnos arrastrar por ella.

Sería digno de mencionar aquí como mi madre me recriminaba durante mi reciente visita a Cuba, porque, según ella, yo decía palabras "imposibles de entender," cuando hacíamos las necesarias charlas de la madre y el hijo que han estado separado por más de 15 años. Es obvio que durante mi discusión de este día ya habrán notado ustedes esta influencia en mi modo de hablar, y aunque me cuido mucho de ella, no puedo evitarla completamente.

Pero el español coloquial americano, como podríamos llamarlo, si nos atrevemos a denominar esta jerigonza, es una expresión del "melting pot" que viene sucediéndose en los Estados Unidos, y que, como todos saben, va más allá de la lengua misma. Pero como la lengua es el gran tazón que contiene a la cultura, ejerce su enorme influencia sobre los hablantes de una manera ineludible y poderosa, a pesar de los miedos de ciertos círculos en Washington por la invasión desenfrenada de inmigrantes. Esta mezcla se está sucediendo hoy con la fuerza demoledora que impone la historia.

Si nos fijamos bien, veremos el tremendo trabajo lingüístico que lleva a cabo el emigrado latinoamericano que va a Estados Unidos. Este hombre lleva consigo a la nueva tierra junto a la esperanza de mejoramiento economico y social, una gran cantidad de los voluminosos bártulos de nuestra rica cultura, "amerindafricanoespañola". 
La re-colonización del hispano en América Anglosajona va más allá, como ya se ha dicho, de sustituir el catsup por la salsa picante. De paso diré que después que esta estadística salió a la luz, los gringos empezaron a discutir seriamente la posibilidad de erigir una regia muralla en California y Texas, para evitar el continuo flujo de la inmigración ilegal. Pero como otro muro no podía construirse después de tumbar uno con tanto "bombo y platillo," y a alguien se le ocurrió decir que esta política, para ser justa, debería incluir la eliminación de los nombres mismos de las regiones en cuestión, los comentarios antiemigrantes de estos intrépidos constructores de murallas, tomaron otro tono.

Este drama lingüístico de asimilación que comenzó con la llegada de Colón, sigue sucediéndose hoy a todo tren. El español de Estados Unidos ha llegado a ser una contundente mezcla de todas los coloquios latinoamericanos, que junto a la poderosa influencia del inglés, forman un calidoscopio lingüístico único y característico. Es por esto que los amantes del castellano nos encontramos hoy enfrascados en una lucha sin cuartel para, según nuestras orgullosas pretensiones, mantener la pureza de la lengua española. Aunque yo pienso que esta pureza está más bien reflejada en la mezcla misma. Desde luego, que debe seguirse alguna regla, y no podemos considerar correctas todas las expresiones que la gente dice. Es muy difícil, sin embargo, encontrar el verdadero límite de lo que debe o no debe usarse en el coloquio.

Existe hoy en Estados Unidos una verdadera lucha entre agencias e instituciones sobre cómo debe hablarse y escribirse la lengua española. Esto se debe a que la gran diversidad y asimilación de la que hemos hablado ha contaminado el uso correcto de la lengua. Hay muchos que hablan de los distintos dialectos del español inherentes a cada nacionalidad, $y$ muchas veces se usan expresiones y palabras que no están correctas, y se achacan a las diferencia entre coloquios. Estas expresiones aunque siguen estando erradas, si le aplicamos la rigurosidad de la academia, son en realidad las que la gente entiende y a través de las cuales se comunica.

Recuerdo que en 1988, produje un video informativo sobre el peligro de consumir alcohol que corren los jóvenes. Por meses busqué afanosamente en todas las agencias artísticas de Chicago a un par de niños que hablaran correctamente el castellano. Al final tuve que contentarme con una pareja, que aunque era muy talentosa y original frente a las cámaras, su español no estaba al nivel que yo buscaba. Después de largas discusiones con mi equipo, y de entrevistar a muchos adolescentes en escuelas públicas y privadas para familiarizarnos con el coloquio de los jóvenes, llegamos a al conclusión que todos estos chicos compartían el mismo modo de hablar, y si nuestro video 
verdaderamente pretendía alcanzarlos y disuadirlos del consumo de alcohol, debíamos presentarlo en su propio idioma, por muy defectuoso e híbrido que nos pareciera. Así lo hicimos y nuestro video fue todo un éxito. Véase aquí de nuevo como se impone lo práctico sobre lo teórico.

En este punto debo advertir que no abogo por la abolición de las reglas gramaticales y lingüísticas, porque éstas son estrictamente necesarias y su ausencia nos dejaría en el caos. Sólo digo que se debe mirar desde el punto de vista de que las lenguas se están mezclando rápidamente y estamos atravesando el proceso lógico de experimentación. A su debido tiempo las academias recogerán de nuevo las expresiones y palabras nuevas, le harán las modificaciones pertinentes, $y$ las usaremos sin ningún reparo en la lengua "correcta".

Si entendemos este proceso de hibridación como lo que es, el nacimiento de una nueva lengua, podríamos hacernos entonces estas preguntas: ¿Cómo hablaremos en Estados Unidos en el año 3000? ¿Llegará el espanglish a convertirse en toda una lengua? ¿Será éste entonces la continuación de lo que ya ha establecido la historia misma?

No olvidemos que en este mestizaje bárbaro, como lo llaman algunos, el castellano lleva las de perder. Esto es obvio, principalmente en las traducciones que se han visto obligados a producir tanto el sector privado como los gobiernos estatales y de las ciudades de Estados Unidos, para enfrentar la invasión de gente que no habla inglés.

Como todo ha ocurrido rápidamente desde el punto de vista lingüístico, y existe hoy una verdadera carencia de hispanos educados en Estados Unidos, el producto ha sido nefasto. Estas traducciones aparecen con una sintaxis "a al inglesa" que da desde risa hasta pena.

Recuerdo un documento que recibi del Departamento de Salud de los Estados Unidos en la agencia publicitaria en donde trabajaba a finales de los 80. Tratábase de cómo evitar el contagio del SIDA, y de la práctica del "safe sex" o sexo seguro que se ha puesto de moda en América debido a la tragedia de esta terrible enfermedad. En uno de incisos de este documento daban consejos de cómo escoger su compañero sexual. Pero como la palabra inglesa "partner" puede significar pareja. El inciso rezaba; "Evite la promiscuidad, escoja una pareja sana para hacer el amor". Sobran los comentarios.

En Estados Unidos está ocurriendo un mestizaje lingüístico sin precedentes que no puede ser detenido por ningún gramático y mucho menos por intrépidos políticos constructores de murallas a prueba de ilícitos. Y porque la mezcla ocurre en el mismo seno del pueblo, que es en definitiva el dueño absoluto de la lengua, pasa inadvertida para las élites, siendo tan imposible de prevenir como de controlar. 
Pero esta influencia no es, ni mucho menos en un solo sentido. El inglés estadounidense también está recibiendo a diario la invasión del castellano. Estas expresiones mixtas se usan a en televisión, radio y prensa escrita sin ningún reparo para alcanzar una audiencia mixta donde el consumidor hispano es de importancia suma.

Muchas expresiones en español que ya son de dominio del público en general, y se han establecido cómodamente en la lengua inglesa. Podríamos citar algunas como. "El número uno" cuando se refieren al mejor, o el virtuoso, cuando se trata de un talento extraordinario, aunque ésta viene más bien del italiano. "Adiós amigos", se usa para despedir a alguien, o advertir lo que pasaría en una catástrofe, y "nada" cuando se habla de la ausencia o falta de algo.

El cine norteamericano no es una excepción a esta tendencia de dejar caer expresiones españolas en la lengua inglesa. Vemos como muchas expresiones españolas son usadas en la pantalla grande por las estrellas de los grandes films. Cuando el forzudo Arnold Schwarzeggher le dijo a su bella acompañante durante uno una de sus películas, la famosa frase de "hasta la vista baby" antes de rociarla con balas, estaba reflejando sin lugar a dudas esta nueva corriente lingüística.

Toda esta mescolanza ha despertado un gran interés en los círculos sociales estadounidenses, que va más allá del coloquio y la lengua escrita. La música popular también se ha hecho eco de esta trasformación. El nuevo ritmo TexMex, impuesto por la tejana extinta, Zelena, ha venido a influir aún más en este sentido.

La rapidez con que ocurre el cambio ha dejado sus huellas y se pueden escuchar en las estaciones de música popular. Se usan una sarta de vulgaridades, disparates y groserías que indudablemente están allí por el desconocimiento absoluto de un "bilingüe de última hora" que produce el programa. Pero como los hispanos nos hemos puesto de moda en E.E. U.U. y nuestra influencia crece cada día más, ha provocado el miedo y la desconfianza en aquellos que ven su país invadido por estas gentes morenas, que hablan muy alto, tienen muchos hijos, comen demasiado, sin prestarle atención alguna al colesterol, y hablan una lengua que se introduce cada vez más en las fibras sociales. Hasta altas esferas del gobierno ha llegado nuestra lengua, cuando los hispanos logran escalar altas posiciones. Esto, entre otras cosas, ha alimentado la fobia antiemigrante que se vive hoy en Estados Unidos.

Este es un buen ejemplo de la ascensión del castellano: Cuando el presidente Clinton escogió a su nuevo Secretario de Transporte, el tejano Federico Peña, los primeros noticieros en inglés hicieron caso omiso de la tilde de la ñ, y los comentaristas lo llamaron Pena durante mucho tiempo. 
Hasta que el secretario explicó un día en televisión, un poco malhumorado, que Pena y Peña no eran la misma cosa, y hasta que no se pusiera la tilde sobre la n, él no se daría por aludido.

Esto es muy importante, agregó entonces un cómico hispano durante un popular programa en español, porque ¿qué pasaría si estuviéramos hablando de año y olvidaros la tilde de la ñ (ja, ja ja). Demás está decir que empezando por $\mathrm{CNN}$, y terminando por la $\mathrm{ABC}$, todas las redes televisivas nacionales le agregaron la tilde a la $n$, naciendo así la ñ en el abecedario televisivo gringo. Anotemos un triunfo más del castellano sobre la competencia.

Los hispanos se han puesto de moda en Estados Unidos ya he dicho. Este auge nos ha ganado simpatizantes y críticos. Algunos piensan que deben pasarse leyes para obligar a la gente a hablar solamente inglés. Que deben eliminarse los programas bilingüies de las escuelas públicas (no por favor que pierdo mi trabajo) o que simplemente debería obligarse a la gente a hablar inglés por la fuerza. Los simpatizantes abogan por el bilingüismo, alegando que la diversidad cultural es la verdadera divisa del país de Lincoln, y se anotaron una victoria cuando se derrotaron en las urnas de Florida y California leyes que pedían el "English only".

La propuesta 187 del gobernador californiano Pete Wilson, que prohibe brindar servicios gubernamentales a los emigrantes ilegales ha venido ahora a calentar aún más los ánimos sobre los emigrantes y toda su influencia en la cultura norteamericana, incluyendo el derecho de poder hablar nuestro propio idioma donde nos de la gana. Pero después que se descubrió que Wilson había empleado a una mexicana ilegal para que fuera su criada, y que como ésta sólo hablaba español, los Wilson se vieron obligados a aprender alguna que otra palabrita en castellano para comunicarse con su sirvienta, el público dejó de creerle, aunque su famosa propuesta triunfó en las urnas y ahora está en la manos de las "cortes", quiero de decir de los tribunales.

Los números rigen a la sociedad norteamericana, y desde que se supo que los hispanos seremos al minoría más grande en el país en el año 2010, aún más numerosa que la población negra, a mucha gente se le puso la carne de gallina. Pero lo más que enoja a nuestros críticos es que los hispanos nos negamos a dejar nuestras costumbres y nuestra lengua a pesar del paso del tiempo. Lo que me parece más curioso es que nosotros, a pesar de la asimilación cultural y económica que sufrimos, hemos mantenido nuestra lengua viva, aunque un poco debilitada, si se quiere, 'y hasta media híbrida, pero viva. Debo decir que este es un fenómeno casi exclusivo de los inmigrantes hispanos estadounidenses. $\mathrm{Y}$ aunque es verdad que otros inmigrantes siguen hablando sus lenguas, nunca éstas se han hecho tan importantes como el cas- 
tellano. El caso de irlandeses, italianos y alemanes, entre otros, son un buen ejemplo de ésto. Estas gentes que nos precedieron en el camino angosto de la inmigración fueron completamente asimilados por la cultura y la lengua predominante, y sus descendientes olvidaron su idioma y sus costumbres maternas.

Podría decir sin lugar a dudas que es quizás el bajo nivel cultural de la mayoría de los hispanos que emigran a Estados Unidos, huyendo de la pobreza y la represión política que ha flagerado a nuestro desgraciado continente desde la llegada del Gran Almirante, la que nos ha salvado de la total asimilación cultural. Es algo sumamente paradójico que la misma ignorancia salve a la cultura.

Actualmente, sin embargo, se ha visto un aumento significativo en la presencia hispana en las universidades y otros centros de enseñanza superior en Estados Unidos, y ha mejorado considerablemente el uso del castellano en la prensa escrita, radial y televisada. Estos hispanos, podría decirse, son en su mayoría pertenecientes a la segunda generación de inmigrantes. Pero como siempre una base fresca y vibrante de "buena lengua" llega con los que siguen entrando al país constantemente, siempre hay un banco abundante de referencia a disposición del lingüista.

La propaganda comercial en español ha sido mayormente la responsable de este desarrollo y auge lingüístico. Las grandes empresas invierten millones de dólares cada año, y en forma creciente, en mensajes comerciales, publicaciones y programas de todo tipo en idioma español. Quieren alcanzar a la enorme audiencia hispana que crece sin cesar. Considérese aquí que en 1994 el poder adquisitivo de los hispanos en Estados Unidos ascendió hasta la descomunal cifra de $\$ 150$ billones. Pero en este nuevo "gold rush" de escribirlo todo en español, los desatinos de algunos son dignos de mención. Daré algunos ejemplos; Un gran fabricante de automóviles sacó su nuevo auto llamado "Nova" al mercado hispano. Ignorantes de lo que esta palabra significaba en español hicieron su campaña a bombo y platillo, pero no pudieron vender mucho. Sea por que el anunciante, no muy ducho en la pronunciación castellana, cometió el error de hacer una pausa inadvertida donde no iba, o porque el nombrecito no inspiraba mucha confianza aunque estuviera bien dicho. No pudieron comprender por qué el fracaso de tanta propaganda multimillonaria, hasta que un cubano listo le dijo al gringo. "Ese carro NO-VA, chico", Y así quedó concluido este triste capítulo del carro que NOVA a ninguna parte.

Recuerdo una conversación que sostuve con un alto ejecutivo de la cadena de tiendas estadounidenses "White Hen" cuando trazábamos la estrategia comercial en español. Yo le propuse en mi calidad de Director Creativo 
de la mayor agencia hispana del Medio Oeste, que le llamáramos "La Gallinita Blanca" en vez de "El Pollo Blanco" como ellos querían, porque me pareció un nombre más simpático y prometedor. El ejecutivo dejó el asunto en mis manos diciendo, que cualquier cosa que dijéramos para atraer al fiel mercado hispano sería bienvenida. Y terminó añadiendo "Ustedes son los consumidores perfectos". Podremos decir entonces, que como en la antigua Mesopotamia, el mercado y no la cultura es la fuerza detrás del desarrollo de la palabra escrita.

Si vemos como crecen los hispanos en Estados Unidos hasta el punto de implantar su lengua como segundo idioma, nos damos cuanta de la importancia que adquiere cada vez más el español. Si usted se da un viaje a Miami, por ejemplo, encontrará tiendas en la "saguesera" (viene de la palabra South West) donde aparece un aviso que reza "We Speak English," donde debía decir "Se habla Español" ésto es, sin lugar a dudas, otro rotundo triunfo de nuestra lengua.

Y si consideramos que hoy viven más de 25 millones de hispanos en Estados Unidos, y que este es el cuarto país en población de habla hispana del mundo entero, sabemos que estos números no pueden pasarse por alto $y$ que explican el miedo que inspiramos. Sólo se debe ver un desfile puertorriqueño o mexicano en Chicago o Nueva York, o un festival de la calle ocho en Miami, para comprender impresionado, el gran poder que ejercemos hoy los hispanos en el destino estadounidense.

No existe un lugar en el mundo donde se ponga de manifiesto con más evidencia la diversidad y amplitud del castellano que entre los hispanos que vivimos en Estados Unidos. Y aunque nosotros no tenemos necesidad de pedir el deletreo de las palabras para entendernos cuando hablamos, como tienen que hacer los norteamericanos, a veces nos encontramos con gentes de otros pueblos que aunque hablan español como nosotros, dicen cosas que simplemente no entendemos.

Esto ocurre hasta dentro de un mismo país. Recuerdo un caso algo jocoso de cuando era un niño. Nos habíamos ido a Camagüey, provincia al este del Cuba (yo soy de la parte central) para asistir a la boda de uno de mis numerosos primos. Estábamos todos armando unas cajitas de cartón pequenitas que contendrían los refrigerios para los invitados. La suegra de mi primo me pidió que llevara para la sala un gran grupo de cajitas ya terminadas. "Ponlas en el confidente" me dijo. Yo me fui a la sala desconcertado y no encontré nada con este nombre. Ocurrióseme ponerlas sobre el sofá, pues me pareció un lugar apropiado. Como no hubo ninguna protesta, pregunté si estaban bien donde las habla puesto; " $\mathrm{Si}, \mathrm{Si}$ — contestó mi interlocutora 
camagüeyana- "El confidente es el lugar prefecto." Aquel día supe que ese era el nombre que le daban en Camagüey a los sofás, y me pareció apropiado porque el sofá, por sentar a muchos, es un buen lugar para hacer confidencias. Después de todo existen en nuestra lengua algo de aquello que tenían los indios de decir para que servían las cosas.

Si aún dentro de un mismo país se notan estas diferencias, las de un país a otro son profundas.

Considérese este texto de uno de mis cuentos llamado el Güije, donde se describe la fauna que vive en un árbol que acaba de ser alcanzado por un rayo:

"Una centella poderosa cayó sobre el almendro rajándolo de arriba a abajo. Las hojas se marchitaron y los habitantes del árbol se disponen a mudarse. Trescientos totíes, veintinueve bijiritas pintas, ciento siete chinchilas, tres mil tomeguines del pinar y de la tierra, trescientas trece tojosas, ciento un cernícalos comedores de gallinas, diez y seis sinsontes trinadores, setecientos setenta zunzunes chupadores de flores y seis sabaneros cantarines. Sin contar con lagartijas, jubos, chipojos, chicharras, ciempiés, chinches de monte, caballitos del diablo, y abejorros de toda índole, que en gran número han vivido en el almendro por generaciones. ¡Se acabó lo que se daba! Todo el mundo se marcha rápidamente porque la electricidad del rayo ha envenenado la madera". (Explicación de las nuevas palabras) Ahora veamos un fragmento de mi novela Cuba-La Huida, donde describo las prácticas de curandera de mi abuela. Panchita.

"-Ahora ustedes van a ir a buscarme yerbas, hijitos - nos dijo la vieja

Entre las escogidas habían hojas de sábila, flores del romerrillo, y ramas de apasote, hojas de ciguaraya; que hay que pedirle permiso antes de cortarla, las frutas del huevo de gallo, pencas de papayo, atejes maduras, caimitillos $y$ jobos.

Se quedó en el portal frotándose las manos para aliviar la impaciencia hasta que volvimos con las yerbas. Después lo inspeccionó todo con detenimiento, como si las estuviera mirando adentro para ver si tenían los poderes que necesitaba para curarle las quemaduras al perro, Jíbaro. Escurrió los largos pecíolos de las hojas del papayo para sacarle la leche, y se la agregó a los demás ingredientes junto con las dormideras que ya se habían abierto. Lo machucó todo en una jícara, que sólo usaba para preparar remedios caseros, y fue mezclándolo poco a poco con miel de la tierra que guardaba en un tarro de buey escondido en el guano del techo de la cocina para que se curara con la humareda del fogón de leña." 
¡Que diversidad tan amplia la de nuestro idioma! ¿Será menester describir lo mencionado?

Pero esta diversidad no sólo ocurre con palabras desconocidas, también en el uso mismo de la lengua: Dígole yo a uno de mis alumnos de origen mexicano que es campeón en dar excusas para no entregar sus tareas: "Quiero este trabajo ahora mismo" él, con muchos nervios me dice: "Ahorita, maestro ahorita." Yo le contesto con tono de autoridad: "Ahorita no, lo quiero ahora". El chico desconcertado, me dice "pues si maestro, aquí lo tiene pues, ahorita mismo".

Lo que pasa aquí es una diferencia en el significado de la palabra "ahora." Cuando los cubanas decimos ahorita, queremos decir "de aquí a un rato", sin embargo, para los mexicanos se refiere al mismo instante.

Es también interesante que cuando los cubanos decimos los diminutivos con tico, cundo los mexicanos usan el tito; Ej. galleticas, vs galletitas; goticas en vez de gotitas, etc. Considérese por otra parte el uso que le dan los argentinos al "vos" como si fuera la segunda persona del singular y no la segunda del plural. Dícese entonces; Vos no sabés, envés de; Tú no sabes. Por qué ocurren estas diferencias entre los hablantes de una misma lengua, es tema para una investigación más profunda y seria. Sólo ahora diremos que se presta a confusión sin lugar a dudas.

Imagínense si estas diferencias que ocurren entre los hispano parlantes se juntan a la influencia que ejerce el inglés.

Pero el fenómeno más grande, y quizás el más desconcertante es la mezcla indiscriminada de los dos idiomas en el habla popular, sin ninguna pauta más que la ley del menor esfuerzo. Consideremos la anécdota de un mejicano mojado (dícese de los ilegales porque supuestamente deben cruzar el río Bravo) recién llegado a Estados Unidos. Este mexicano está ayudándole a reparar un automóvil a un paisano suyo que llegó desde muy pequeño.

Mientras el mojado está dentro del auto, el otro desde afuera le grita "estaréalo, estaréalo" (del inglés "to start"). El hombre no entiende nada, hasta que su compañero le grita malhumorado: ¡Que los arranques buy!

Estas palabras tienen un uso generalizado entre amplias esferas de la población, mayormente en las más incultas. Sin embargo, es difícil de encantar un hispano en Chicago, no importa su nivel cultural, que vaya a almorzar sino a "lonchar," o se vaya de viaje el fin de semana sino el "weekend", o que se tome un receso sino "un brake", o que tenga que "taipiar" (viene de typing) en vez de escribir algo a máquina. También te pueden invitar a un "coffee" en vez de a un café, o un "barbiquiu en la yarda" en lugar de a un asado en el patio. Puedes tener una vecina "nursa" en vez de enfermera, e ir 
a la "groceria" (de groceries) en vez de a la tienda. Y oír la monumental frase de "no te sientes en la window, que te caes pa'l street".

Hace algún tiempo atrás fui testigo de una disputa entre una filipina llamada Dolores Maravilla, pero que no habla español, y un cubano balsero (llegó a Estados Unidos en un balsa procedente de Cuba) que, por supuesto, no entiende inglés. Discutían éstos dos airadamente, y la filipina le dice al cubano, usando su pequeño vocabulario en la lengua de Cervantes: "Tu Pepe... no bueno, mucho problema, mucho bla bla bla." El cubano se queda pensando profundamente qué palabra podía decirle para ofenderla, pero como no sabe muchas, recordó que un compañero gringo lo había llamado un día; "Ass," es decir burro, entonces se le acercó a la Maravilla, y con el tono más agresivo que pudo le gritó; "YU ASA, ASA"; haciendo el necesario ajuste para admitir el género de la palabra.

Sin dudas que la exuberancia americana puso a prueba al castellano, desde que Colón dijo aquella frase de, "Esta es la tierra más fermosa que ojos humanos han visto," Ahora podíamos nosotros decir; "Esta es la lengua más diversa que ojos humanos han visto." Y probablemente no estemos equivocados. 